\title{
METODA PEMBUATAN SENYAWA ORGANOIODIUM TURUNAN SUKROSA DI DALAM FRAKSI AIR
}

\author{
Pratama Jujur Wibawa, Isniningsih \\ Laboratorium Kimia Organik Jurusan Kimia \\ F MIPA Universitas Diponegoro Semarang 50275
}

\begin{abstract}
ABSTRAK
Dalam penelitian ini telah berhasil membuat senyawa organoiodium turunan sukrosa di dalam fraksi air dengan cara mereaksikan sukrosa, iodium dan fosfor merah di dalam set alat refluks pada suhu $98^{\circ} \mathrm{C}$ selama 15 menit. Pada akhir reaksi, campuran diekstraksi menggunakan n-heksana dan fasa atau fraksi air yang terbentuk dipisahkan dari fasa organiknya. Fasa air ini kemudian ditotolkan pada plat KLT yang dibuat dari gel silika $60 F_{254}$ dan dikembangkan dengan campuran butanol: asam asetat: air (BAA, 4:1:5). Dari perlakukan ini diperoleh satu noda yang mempunyai Rf 0,6. Noda ini kemudian, diekstraksi menggunakan metanol dan dianalisis menggunakan spektrofotometer merah infra (MI). Noda ini memunculkan spektra yang khas pada bilangan gelombang $615,2 \mathrm{~cm}^{-1}$. Hal ini berarti ikatan C-I yang diharapkan berhasil terbentuk dan sekaligus menunjukkan bahwa fasa air tersebut mengandung senyawa organoiodium turunan sukrosa.
\end{abstract}

Kata kunci: organoiodium, senyawa turunan sukrosa

\begin{abstract}
The aqueous organoiodine derived from sucrose could be produced from reaction of sucrose, iodine and red phosphorous in a set reflux equipment on $98^{\circ} \mathrm{C}$ for 15 minutes. After the reaction time was over the mixture was then extracted with $n-$ hexane, and the aqueous phase yielded was separated from organic phase. The aqueous phase was introduced on a $60 F_{254}$ silica gel TLC plate with development liquid was butanol: acetic acid: water (BAW 4:1:5). It was showed one mark with Rf of 0.6. This mark was then scraped and extracted with methanol and analyzed by FTIR spectrophotometer. This mark appeared specific IR spectra in wave number of $615.2 \mathrm{~cm}^{-1}$ which was indicated that C-I bond have been succeed formed. Those mean that an organo iodine desired was present in the aqueous phase.
\end{abstract}

Keywords: organo iodine, sucrose derivative compound

\section{PENDAHULUAN}

Sekitar 37 juta penduduk Indonesia ditengarai menderita gangguan kesehatan akibat kekurangan iodium (GAKI). Penduduk sejumlah itu pada umumnya tinggal di daerah-daerah pegunungan dan tersebar di hampir seluruh propinsi di Indonesia (Harian Republika, 1997). Di tingkat dunia, WHO mencatat hingga tahun 1990 tidak kurang dari 1,5 miliar penduduk dunia terancam GAKI. GAKI merupakan penyakit lama masyarakat yang dapat menyebabkan terhambatnya perkembangan fisik, psikis dan kecerdasan seseorang. Keadaan ini akan menjadi ancaman serius bagi program peningkatan kualitas sumber daya manusia (SDM) tidak saja di Indonesia tetapi juga di seluruh dunia. Oleh karena itu diperlukan penanganan secara serius untuk mencegah terjadinya tragedi kemanusian di massa depan.

Untuk menanggulangai masalah GAKI, WHO merekomendasikan agar dilakukan iodisasi pada semua garam makan dan garam-garam lainnya yang biasa dikonsumsi oleh masyarakat. Sampai sejauh ini, iodisasi garam dilakukan dengan menggunakan $\mathrm{KIO}_{3}$ hingga konsentrasi 30-80 ppm. Dengan menggunakan $\mathrm{KIO}_{3}$ ternyata banyak dijumpai kasus terjadinya penurunan bahkan kehilangan kadar iodium pada garam-garam beriodium selama massa penyimpanan. Hal ini kiranya merupakan salah satu penyebab terhambatnya program penanggulangan penyakit GAKI di Indonesia. Diyakini, hal ini disebabkan $\mathrm{KIO}_{3}$ mudah tereduksi menjadi gas $\mathrm{I}_{2}$ yang bersifat volatile sehingga pada kondisi atınosferis akan mudah menguap. Proses ini akan makin mudah terjadi jika garam bersifat sedikit asam dan lembab oleh air (Saksono et al, 1998).

Untuk mengatasi kelemahan $\mathrm{KIO}_{3}$ ini maka perlu dibuat senyawa organoiodium yang bersifat kovalen, yaitu mensenyawakan unsur iodium dengan molekul organik secara kovalen. Dengan ikatan kovalen ini, unsur iodium tidak mudah tereduksi menjadi gas $\mathrm{I}_{2}$ sehingga dapat tetap stabil berada di dalam garam atau bahan makan lainnya selama penyimpanan. Dalam hal ini molekul organik yang dipilih sebagai pembawa unsur iodium adalah sukrosa. Sukrosa merupakan disakarida penyusun utama gula tebu dan banyak memiliki gugus hidroksil yang secara kimia berperilaku seperti gugus hidroksil alkohol. Alkohol cukup mu- 
dah mengalami reaksi substitusi nukleofilik menjadi alkil iodida apabila direaksikan dengan fosfor merah dan iodin. Dalam kaitan ini, Smith(1994) menulis bahwa cetil alkohol, $n$ - $\mathrm{C}_{15} \mathrm{H}_{31} \mathrm{OH}$ dapat dikonversi menjadi cetil iodida, $n-\mathrm{C}_{15} \mathrm{H}_{31} \mathrm{I}$ dengan merefluks alkohol tersebut bersama-sama dengan fosfor merah dan iodin pada suhu $150^{\circ} \mathrm{C}$, dan diperoleh produk sekitar $85 \%$.

\section{METODA PENELITIAN}

Bahan - bahan:

Sukrosa sebagai molekul organik. Fosfor merah p.a. dan Iodin p.a. sebagai pereaksi. $n$-Heksana dan Metanol sebagai pelarut untuk ekstraksi produk. Plat KLT silika gel $60 \mathrm{~F}_{254}$ untuk memisahkan produk.

Alat-alat :

Satu set alat refluk, beberapa peralatan gelas standar, pengaduk magnet, penguap putar vakum untuk memekatkan hasil dan spektrometer FTIR untuk menganalisis produk.

\section{Cara kerja :}

Sebanyak 20 gram sukrosa dilarutkan dalam $50 \mathrm{~mL}$ aquades dan dimasukkan ke dalam labu leher tiga 250 $\mathrm{mL}$. Fosfor merah sebanyak 0,585 gram ditambahkan ke dalam labu tersebut, selanjutnya ditambahkan 5,78 gram iodin sedikit demi sedikit. Campuran dibiarkan selama 10 menit. Campuran ini kemudian dipanaskan selama 15 menit, setelah itu didinginkan pada su-hu kamar dan diekstraksi dengan $n$-heksana. Fraksi nheksana dipekatkan dengan penguap berputar dan dianalisis menggunakan KLT yang dikembangkan dengan butanol-air. Noda tunggal yang diperoleh dikerok, senyawanya diekstraksi dengan $n$-heksana dan dianalisis menggunakan spektrometer FTIR. Demikian pula fraksi air yang diperoleh. Fraksi ini juga dianalisis dengan KLT tetapi larutan pengembangnya butanol:asam asetat:air (BAA) 4:1:5. Noda tunggal yang diperoleh dikerok kemudian diekstraksi mengunakan metanol dan dianalisis dengan spektrometer FTIR .

\section{HASIL DAN PEMBAHASAN}

Dari reaksi sukrosa, fosfor merah dan iodine dapat diperoleh dua fraksi, yaitu fraksi organik ( $n$-heksana) dan fraksi anorganik(air). Analisis KLT terhadap kedua fraksi tersebut menunjukkan bahwa masing-masing fraksi mengandung senyawa tunggal (senyawa murni) yang memberikan pola spektra IR berbeda dari spek- tra IR sukrosa. Spektra IR untuk senyawa yang terdapat di dalam fraksi n-heksana ditampilkan pada Gambar 1. Spektra IR untuk senyawa yang terdapat di dalam fraksi air ditampilkan pada Gambar 2. Spektra IR sukrosa ditampilkan pada Gambar 3.

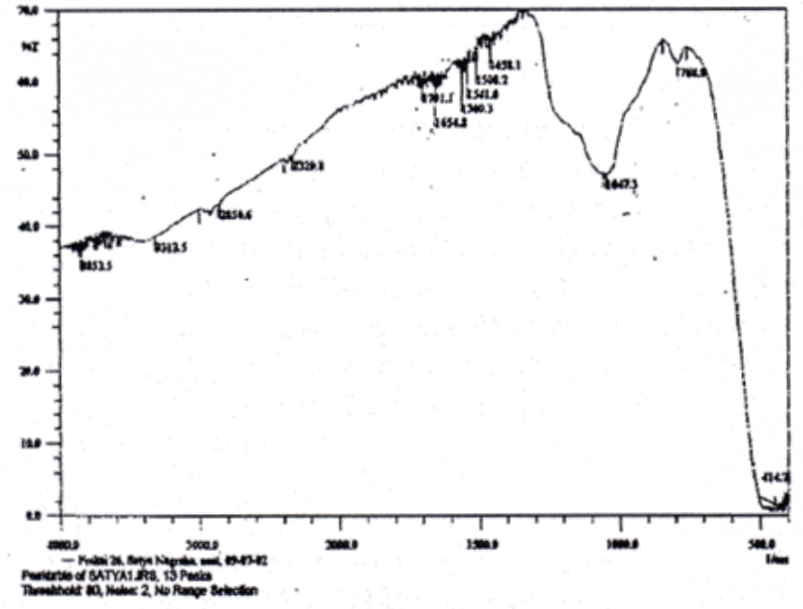

Gambar 1. Spektra IR senyawa X di dalam fraksi n-heksana

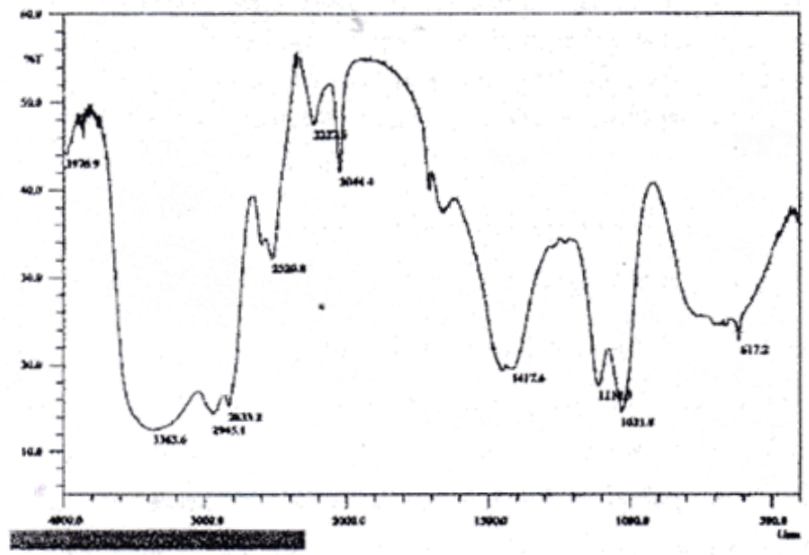

Gambar 2. Spektra IR senyawa Y di dalam fraksi air

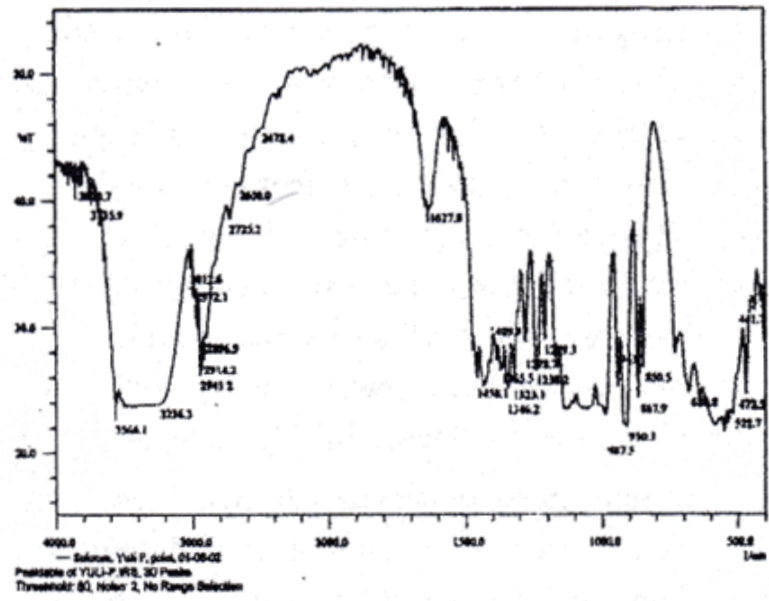

Gambar 3. Spektra IR sukrosa

Dengan membandıngkan ketıga pola spektra IR tersebut, terlihat bahwa senyawa $\mathrm{X}$ yang terdapat di dalam 
fraksi n-heksana maupun senyawa $\mathrm{Y}$ yang terdapat di dalam fraksi air adalah bukan merupakan senyawa sukrosa. Senyawa $X$ juga tidak identik dengan senyawa $\mathrm{Y}$. Dengan demikian baik senyawa X maupun $\mathrm{Y}$ keduanya dapat disebut sebagai senyawa turunan sukrosa. Perbedaan pola spektra IR paling penting antara senyawa X dan $\mathrm{Y}$ adalah bahwa senyawa $\mathrm{Y}$ memberikan puncak khas pada bilangan gelombang sekitar $617 \mathrm{~cm}^{-1}$ sedangkan senyawa X tidak. Puncak di seki$\operatorname{tar} 617 \mathrm{~cm}^{-1}$ ini merupakan vibrasi ulur dari ikatan karbon-iod, C-I yang dalam percobaan ini diharapkan dapat terjadi. Dengan demikian senyawa Y merupakan senyawa organoiodium turunan sukrosa yang diharapkan sedangkan senyawa X bukan merupakan senyawa organoidium. Dengan kata lain, senyawa organoidium turunan sukrosa yang bersifat larut di dalam air dapat dibuat dari sukrosa, fosfor merah, dan iodium

\section{KESIMPULAN}

Berdasarkan percobaan dan analisis produk yang diperoleh, dapat disimpulkan bahwa senyawa organoiodium turunan sukrosa yang bersifat larut dalam air dapat dibuat dengan mereaksikan sukrosa, fosfor merah dan iodium pada suhu $98^{\circ} \mathrm{C}$ selama 15 menit.

\section{DAFTAR PUSTAKA}

1. Anwar, H. M., 1987, Gondok Endemik, Penyakit Kekurangan Gizi paling Tua, Buletin Gizi, 2 (11), hal. 30-36.

2. Pharoah, P. ; Delange, F. ; Stanbury, J. B., 1980, Endemic Cretinism, Endemic Goiter and Endemic Creatinism, John Wiley \& Sons, Toronto, p. 395-459

3. Saksono, N.; Wulandari, L. D. ; Mulia, K., 1998, Stabilitas $\mathrm{KIO}_{3}$ dalam berbagai Kwalitas Garam Indonesia, Jurusan Gas dan Petrokimia, Fakultas Teknik, Universitas Indonesia, Jakarta

4. Smith, M.B., 1994, Organic Synthesis, Int.ed., McGrawHill, New York, p.153-154.

5. Wade, L. G., 1987, Organic Chemistry, Prentice hall Inc., USA, p. 465-467. 
